\title{
Double trouble? Potential for hyperexcitability following both channelopathic up- and downregulation of $I_{h}$ in epilepsy
}

\author{
Jonas Dyhrfjeld-Johnsen ${ }^{1,2 *}$, Robert J. Morgan ${ }^{3}$ and Ivan Soltesz ${ }^{3}$ \\ 1 Harvard Medical School, Boston, MA, USA \\ 2 Neurology, Massachusetts General Hospital, Boston, MA, USA \\ ${ }^{3}$ Anatomy and Neurobiology, University of California - Irvine, Irvine, CA, USA
}

Edited by:

Alexander Borst, Max Planck Institute of Neurobiology, Germany

Reviewed by:

Nelson Spruston, Northwestern

University, USA

Valentin Stein, Max Planck

Institute of Neurobiology, Germany

* Correspondence:

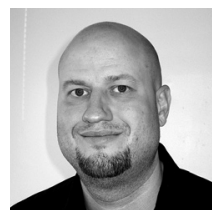

Jonas Dyhrfjeld-Johnsen completed his doctoral degree at the C. \& O. Vogt Brain Research Institute of the Heinrich-Heine University in Düsseldorf with Dr. Rolf Kötter. He started his research career in the epilepsy field in Dr. Ivan Soltesz's lab at the University of California - Irvine. Currently a Research Fellow at Harvard Medical School and Massachusetts General Hospital in the group of Dr. Kevin Staley, his research focuses on pathological changes at the single neuron and local network level in the hippocampus underlying epileptogenesis and recurrent seizure activity.

jdyhrfjeld-johnsen@partners.org

Studies of pathological ion channel regulation as an underlying mechanism of epilepsy have revealed alterations in the h-current in several animal models. While earlier reports indicate that downregulation of the h-current is pro-excitatory on the single neuron level, we found an upregulation of $I_{h}$ in hyperexcitable CA1 pyramidal neuron dendrites following experimental febrile seizures. In addition, in several CA1 pyramidal neuron computational models of different complexity, h-current upregulation has been shown to lead to pro-excitable effects. This focused review examines the complex impact of altered h-current on neuronal resting membrane potential (RMP) and input resistance $\left(R_{\text {in }}\right)$, as well as reported interactions with other ionic conductances.

Keywords: h-current, excitability, acquired channelopathy, epilepsy

\section{INTRODUCTION}

The study of channelopathies, pathological changes in the expression and function of ion channels, has gained momentum in recent years in epilepsy research - several idiopathic epilepsies (inherited) have been linked to underlying mutations in channel encoding genes (for reviews see, Catterall et al., 2008; Hirose et al., 2005; Lerche et al., 2005; Mulley et al., 2003). For the study of the inherited, genetically determined pathologies, a number of experimental models reproducing human mutations and symptoms have been generated (for review see, Avanzini et al., 2007). Similarly, the study of symptomatic epilepsy (developed after a brain insult) in animal models has identified several acquired channelopathies - so named because the channelopathies develop in response to the brain insult or subsequent status epilepticus (for review see, Pitkanen and Lukasiuk, 2009). The channel types affected by the acquired channelopathies include $\mathrm{GABA}_{\mathrm{A}}$-receptor-channels (Brooks-Kayal et al., 1998; Sanchez et al., 2005), voltage-dependent
$\mathrm{Na}^{+}$channels (Ellerkmann et al., 2003; Howard et al., 2007), $\mathrm{Ca}^{2+}$ channels (Becker et al., 2008; Su et al., 2002), and $\mathrm{K}^{+}$channels (Bernard et al., 2004; Howard et al., 2007; Shin et al., 2008; Shruti et al., 2008). However, the most frequently acquired channelopathy concerns the mixed cation $\mathbf{h}$-current in a number of different epilepsy models: perinatal seizure-inducing hypoxia (Zhang et al., 2006), the kainate model of temporal lobe epilepsy (Shah et al., 2004), the pilocarpine model of temporal lobe epilepsy (Jung et al., 2007; Marcelin et al., 2009; Shin et al., 2008), the fluid percussion injury (FPI) model of post-traumatic epilepsy (Howard et al., 2007), and prolonged experimental febrile seizures (Chen et al., 2001a; Dyhrfjeld-Johnsen et al., 2008).

In most experimental paradigms for investigation of the acquired h-channelopathies, a seizureinduced reduction in $I_{\mathrm{b}}$ was reported (Jung et al., 2007; Marcelin et al., 2009; Shah et al., 2004; Shin et al., 2008; Zhang et al., 2006). The downregulated h-current was linked to hyperexcitability and 


\section{Epilepsy}

A family of neurological seizure disorders characterized by abnormal electrical discharges in the brain, resulting in behavioral symptoms ranging from staring spells to intense convulsions and loss of consciousness. Idiopathic epilepsies do not result from an identifiable external cause and are presumed to be genetic, while symptomatic epilepsies have an identifiable cause such as severe head trauma.

\section{Channelopathy}

Pathological expression or function of ion channels, either inherited (genetically encoded) or acquired (developed in response to an injury or insult).

\section{h-Current}

An inward (depolarizing) noninactivating ionic current tonically active at the resting membrane potential. The h-channels are assembled from the channel subunits HCN1-4. The h-current $\left(I_{\mathrm{h}}\right)$ is activated by hyperpolarization of the cell membrane and modulated by cAMP and $\mathrm{pH}$.

\section{Febrile seizure}

A type of seizure caused by high fever in $3-5 \%$ of infants and young children. Prolonged febrile seizures increase the risk of developing epilepsy later in life. seizures through the resulting increase in neuronal input resistance. However, our recent paper on dendritic h-channelopathy in the experimental febrile seizure model reported a $\sim 70 \%$ increase in the h-current density along with depolarized halfactivation potential $\left(V_{1 / 2}\right)$ and slower kinetics in hyperexcitable CA1 pyramidal neuron dendrites (Figure 1). The depolarized $V_{1 / 2}$, along with the overall increase in h-current density, means that smaller stimuli are required to strongly activate $I_{\mathrm{h}}$ from the resting membrane potential (RMP) in CA1 pyramidal neurons following febrile seizures.

This focused review concentrates on recent data on mechanisms of $\mathrm{h}$-current regulation and re-examines the long-standing dichotomy (Poolos, 2004) of potential for both channelopathic upregulation and downregulation of $I_{\mathrm{h}}$ resulting in hyperexcitability.

\section{MECHANISMS OF ACTIVITY-DEPENDENT $I_{\mathrm{h}}$ REGULATION}

In the studies of acquired h-current channelopathies mentioned above, alterations of maximal current levels as well as altered activation properties and kinetics have been reported. Below, we summarize a number of processes that are known to affect hyperpolarization-activated cation ( $\mathrm{HCN})$ channel properties, expression levels, and trafficking with an emphasis on activity-dependent mechanisms.

In addition to the relatively well-established modulation of HCN channel activation by intracellular pH (Munsch and Pape, 1999) and cAMP (DiFrancesco, 1993; Wainger et al., 2001), recent years have seen a number of additional mechanisms impacting the half-activation voltage of $I_{\mathrm{h}}$. This includes allosteric gating by the membrane phospholipid phosphatidylinositol-4,5 biphosphate $\left(\mathrm{PIP}_{2}\right)($ Zolles et al., 2006) as well as activation of the $\mathrm{p} 38$ mitogen-activated protein kinase (p38 MAPK) (Poolos et al., 2006) and diacylglycerol (DAG) (Fogle et al., 2007) signaling pathways who strongly modulate the half-activation voltage of $I_{\mathrm{h}}$.

In plasticity studies, protocols commonly used to induce long-term potentiation (LTP) and long-term depression (LTD) were shown to modulate intrinsic neuronal excitability. Specifically, increased HCN channel protein synthesis resulted in decreased neuronal excitability following the LTP induction (Fan et al., 2005; see also van Welie et al., 2004). This process was shown to depend on calcium influx through NMDA-receptors following action potential (AP) back-propagation and a subsequent, calcium/calmodulin-dependent protein kinase II (CamKII) activation (Fan et al., 2005). Conversely, a downregulation of the h-current leads to increased neuronal excitability following the LTD induction, through the activation of group 1 metabotropic glutamate receptors and the protein kinase $\mathrm{C}(\mathrm{PKC})$ pathway (Brager and Johnston, 2007).

Recent investigations of $\mathrm{h}$-current regulation following kainate-induced seizures in vivo and in organotypic slice cultures have shown a profound downregulation of HCN1 channel expression (McClelland et al., 2008). The reduced expression was linked to a seizure-induced upregulation of neuron-restrictive silencing factor (NRSF), which binds strongly to the HCN1 encoding gene and restricts transcription. Blocking NRSF function prevents seizure-induced reduction of $\mathrm{HCN} 1$ expression.

In the experimental febrile seizure model, a lasting increase in the maximal h-current is accompanied by a depolarized half-activation potential and slower time-constants (Chen et al., 2001a; Dyhrfjeld-Johnsen et al., 2008), while the HCN1 subunit expression is decreased (Brewster et al., 2002). These complex alterations could potentially be explained by a seizure-induced increase in the formation of $\mathrm{HCN} 1 / \mathrm{HCN} 2$ heteromeric channels with different properties than homomeric channels (Brewster et al., 2005; Chen et al., 2001b), through increased glycosylation of HCN1 subunits (Zha et al., 2008).

Not only the density and properties of $I_{\mathrm{h}}$, but also the specific subcellular distribution of $\mathrm{HCN}$-channels are subject to activity-dependent regulation: in CA1 pyramidal cells, the characteristic increasing h-current density along the apical dendrites of CA1 pyramidal neurons (DyhrfjeldJohnsen et al., 2008; George et al., 2008; Lorincz et al., 2002; Magee, 1998) is established and maintained by excitatory input from the enthorinal cortex (Shin and Chetkovich, 2007). Blockade of excitatory neurotransmission results in an even distribution of $\mathrm{HCN}$-channels throughout the neuronal compartments. In recent years, liveimaging of CA1 pyramidal neurons transfected with GFP-tagged HCN1 channels has revealed an immediate and a strong decrease in HCN channel mobility following bath application of glutamate. The decreased mobility resulted from a $>2$-fold increase in the fraction of surface expressed $\mathrm{HCN}$ channel proteins (Noam et al., 2008). These results indicate the potential for rapid activity-dependent regulation of $I_{\mathrm{h}}$ by fast removal or insertion of existing HCN channel proteins. A candidate for such regulation, the chaperone protein TRIP8b, co-localizes with HCN1 subunits in pyramidal neurons (Santoro et al., 2004). Interestingly, a disruption of the interaction between the HCN1 subunits and TRIP8b has been reported as a mechanism underlying the channelopathic mislocation of h-channels in the kainate model of temporal 


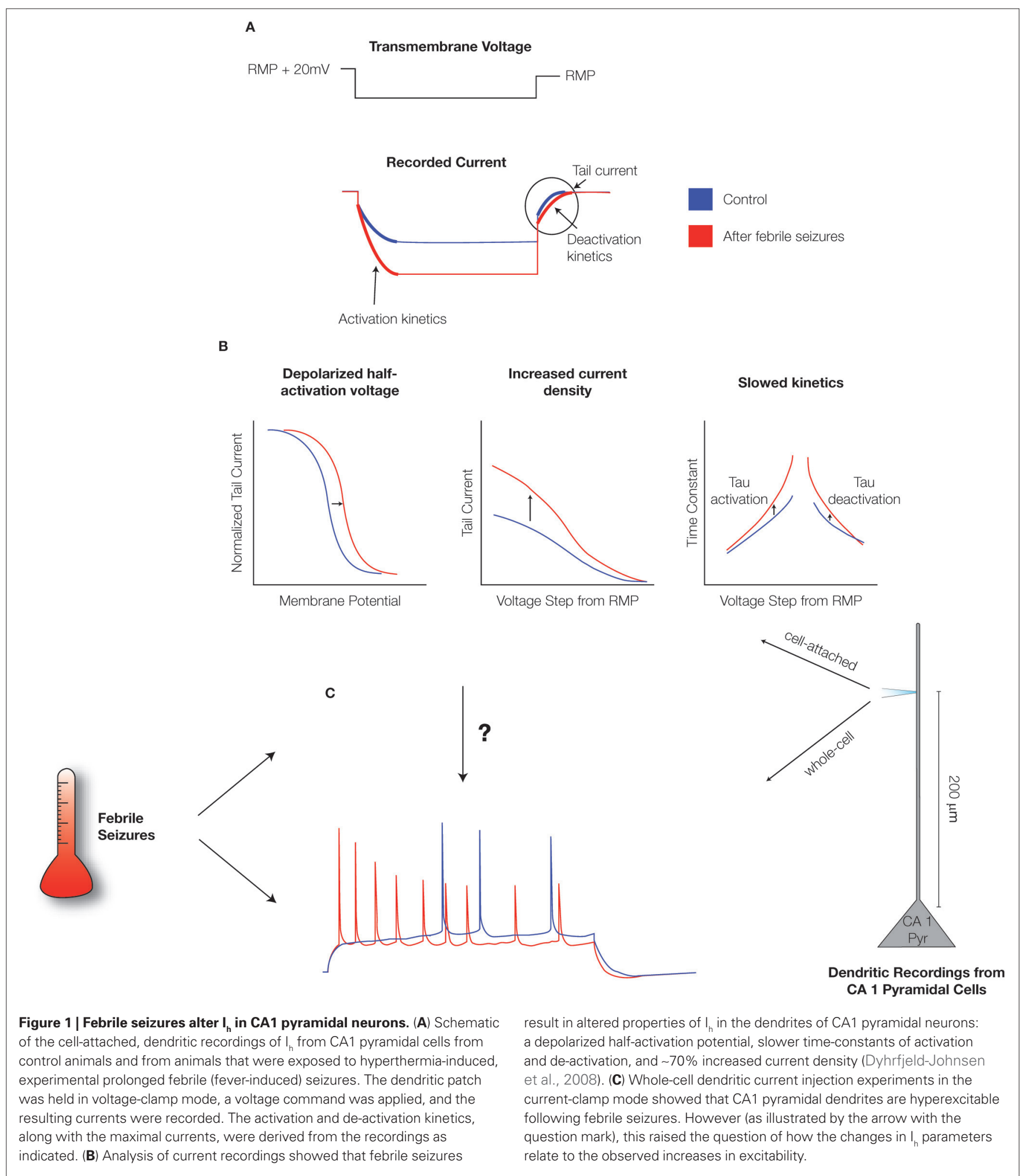

lobe epilepsy (Shin et al., 2008). This suggests that altered h-current densities in epilepsy may not only be due to altered levels of channel proteins, but also depend on altered trafficking and localization of neuronal structures.
UP OR DOWN? AN EXCITING DICHOTOMY

In the study of voltage-gated channel alterations in neurological disorders, a key question is how the plasticity of intrinsic properties affects single neuron excitability (Beck and Yaari, 2008). With 
the multitude of potential mechanisms for regulating $I_{\mathrm{h}}$ expression and characteristics described above, it is perhaps not surprising that different acquired h-channelopathies have been discovered in different animal models of epilepsy. However, an apparent contradiction exists between the studies suggesting that single neuron hyperexcitability results from a downregulation (Jung et al., 2007; Shah et al., 2004) or an upregulation (Chen et al., 2001a; Dyhrfjeld-Johnsen et al., 2008) of the h-current.

\section{UNIQUE PROPERTIES OF THE h-CURRENT}

To explore the dichotomy, it is necessary to bear in mind some unique properties of $I_{\mathrm{h}}$ : the h-current is hyperpolarization-activated and non-inactivating with a reversal potential between -25 and $-40 \mathrm{mV}$ (Robinson and Siegelbaum, 2003), making the current an inward or depolarizing (hence, per definition, an "excitatory") current with respect to the resting potential. $I_{\mathrm{h}}$ is tonically active at the RMP of most neurons (Kaupp and Seifert, 2002), resulting in a contribution to both the neuronal RMP and input resistance $\left(R_{\text {in }}\right)$ as demonstrated, e.g., by the hyperpolarization accompanied by increased $R_{\text {in }}$ following h-current blockade (Magee, 1998) or h-channel deletion (Nolan et al., 2007). By contributing to both the neuronal RMP and $R_{\text {in }}$, the h-current plays a dual role in determining neuronal excitability by influencing the resting distance from the firing threshold of the cell as well as the amount of depolarization caused by excitatory currents.

\section{HANGING IN THE BALANCE: $I_{\mathrm{h}}$ EFFECTS ON RMP AND $\boldsymbol{R}_{\text {in }}$}

When assessing the effect of altered $I_{\mathrm{h}}$, a common practice dictates that recordings are made from a common holding potential. This ensures that other voltage-gated conductances and the membrane voltage relative to firing threshold remain the same in control and altered h-current condition. However, as emphasized in combined computational and experimental studies (Dyhrfjeld-Johnsen et al., 2008; George et al.,2008), this practice masks the excitatory effects of $I_{\mathrm{h}}$ by negating the impact on the RMP, and also on the amount of depolarization required to reach firing threshold.

An increased h-current density leads to a depolarized RMP closer to the firing threshold, but also a decreased $R_{\text {in }}$ due to the increased number of HCN-channels open at rest (Figure 2A). Conversely, a decreased h-current density results in a hyperpolarized RMP further away from the firing threshold, but an increased input resistance due to a decreased number of $\mathrm{HCN}$-channels open at rest (Figure 2A). Injecting a constant current to hold a neuron with altered $I_{\mathrm{h}}$ at the control RMP (Figure 2B) creates a situation in which increased h-current density only leads to decreased $R_{\text {in }}$, while decreased $I$ only leads to increased $R_{\mathrm{in}}$. The effects are further pronounced (Figure 2) when the altered h-current density is accompanied by changes in the half-activation potential: a depolarized $V_{1 / 2}$, along with upregulated $I_{\mathrm{h}}$ density, further increases the h-current at more depolarized membrane potentials (Chen et al., 2001a; Dyhrfjeld-Johnsen

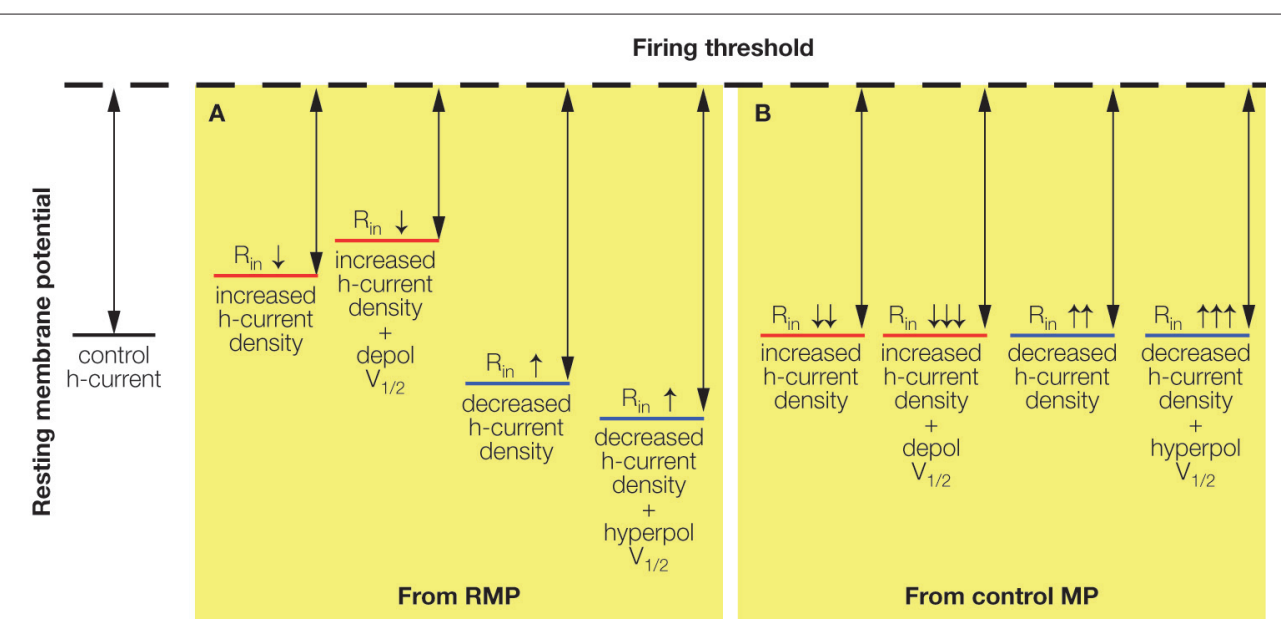

Figure 2 | Effects of altered $\boldsymbol{I}_{\boldsymbol{h}}$ on RMP and $\boldsymbol{R}_{\boldsymbol{i n}}$. (A) Increased h-current density depolarizes the neuronal RMP (bringing it closer to firing threshold) but decreases the $R_{\mathrm{in}}$ (reducing the effect of inputs). Decreased h-current density hyperpolarizes the neuronal RMP (bringing it further away from firing threshold) but increases the $R_{\text {in }}$ (increasing the effect of inputs). The effects on the RMP are further increased when the h-current $V_{1 / 2}$ is depolarized or hyperpolarized in addition to density changes. (B) Holding neurons with altered $/$ at the control resting membrane potential (control MP) abolishes the depolarizing or hyperpolarizing effects on the RMP, but further accentuates the respective decrease or increase of $R_{\text {in }}$ by increased or decreased h-current density. 


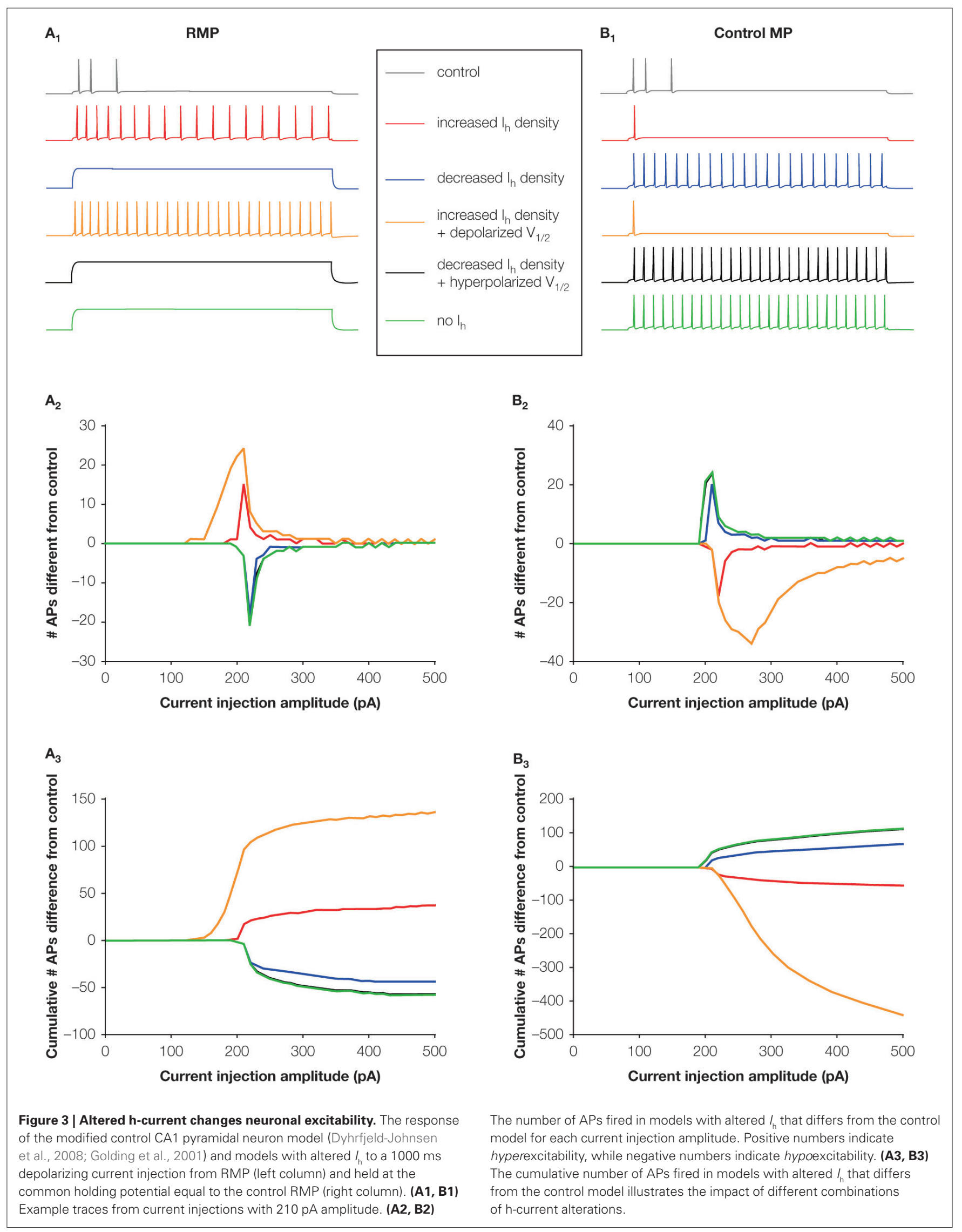


et al., 2008), while a hyperpolarized $V_{1 / 2}$ accompanying downregulated $I_{\mathrm{h}}$ density further decreases the h-current even at hyperpolarized membrane potentials (Jung et al., 2007).

Using a modified version of a previously published CA1 pyramidal neuron compartmental model (Dyhrfjeld-Johnsen et al., 2008; Golding et al., 2001), the direct effect of altered $I_{\mathrm{h}}$ on AP firing in response to the steady-state dendritic current injection can be assessed (Figure 3).

When current injections are performed at the "free-floating" RMP with control or altered h-current levels, an increase in the number of APs fired is seen in the models with increased h-current density, but not in the decreased $I_{\mathrm{h}}$
(Figures 3A1-A3). Conversely, when the models are held at a common membrane potential before the current injection, only the models with decreased $I_{\mathrm{h}}$ fire more APs than the control model (Figures 3B1-B3). Interestingly, even complete removal of the h-current from the model does not result in hyperexcitability from the RMP.

Similarly, excitability-enhancing effects of increased $I_{\mathrm{h}}$ were also obtained using dendritic EPSP summation as outcome measure, in both a relatively simple (Figures $\mathbf{4 A 1}, \mathbf{A} 2$ ) and a more complex (Figures 4B1, B2) model of CA1 pyramidal cells (Dyhrfjeld-Johnsen et al., 2008). In both the models, increased $I_{\mathrm{h}}$ accompanied by a depolarized $V_{1 / 2}$ leads to decreased temporal summa-

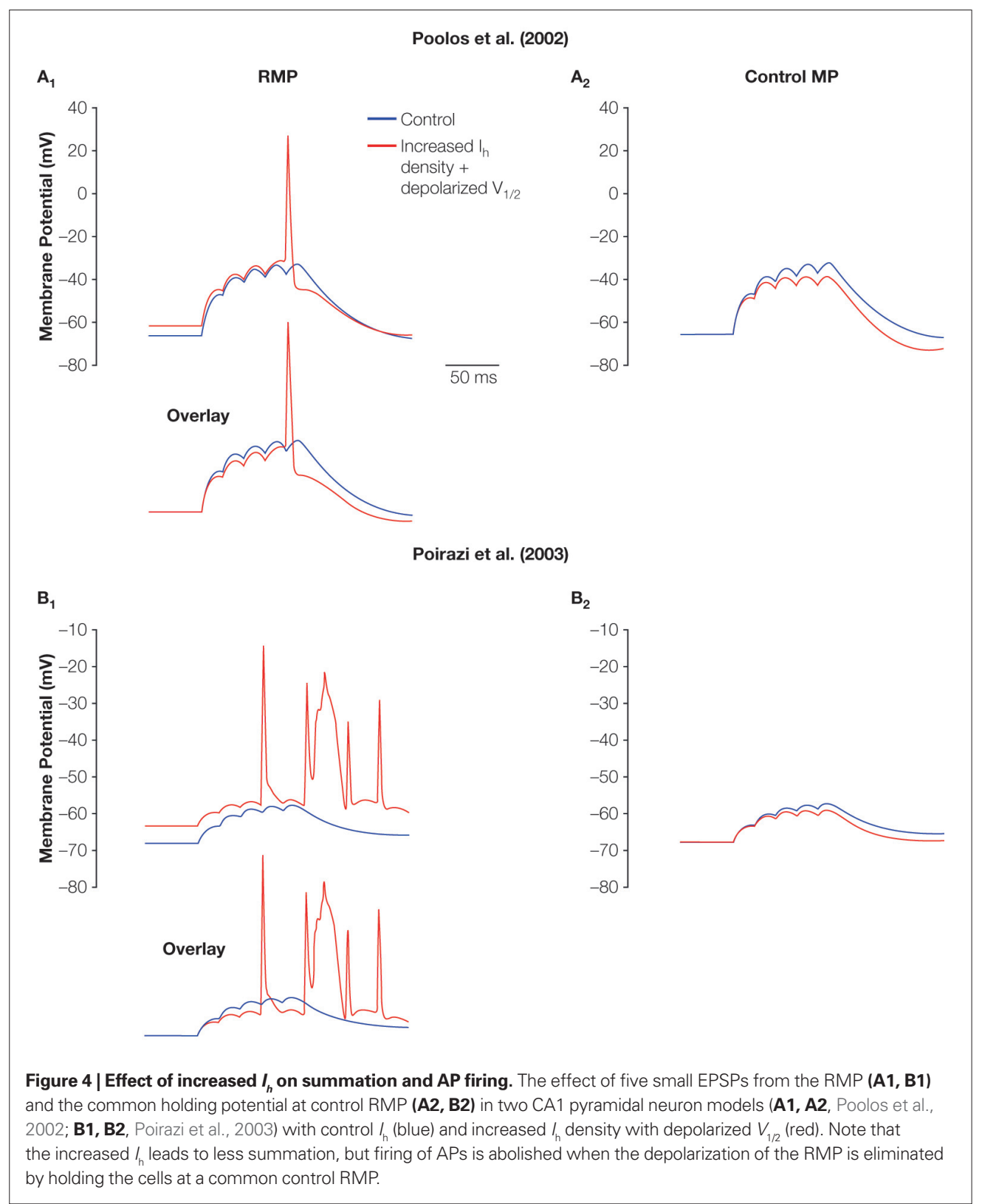


tion of EPSP inputs due to the decreased $R_{\text {in }}$ (see overlays in Figures 4A1,B1). However, models with increased $I_{\mathrm{h}}$ are closer to threshold and fire APs in response to the simulated synaptic input due to the depolarized RMP. From a common control RMP, only the decreased temporal summation due to the decreased $R_{\text {in }}$ remains in the models with increased $I_{\mathrm{h}}$ (Figures 4A2,B2). Therefore, it is important to allow the effects of the altered h-current on both RMP and $R_{\text {in }}$ to come into play when assessing the direct impact on neuronal excitability.

\section{INTERACTIONS WITH OTHER CONDUCTANCES}

The h-current does exert effects on neuronal excitability not only by influencing the RMP and $R_{\text {in }}$, but also through interactions with other voltagegated channels. Recent data show that the shunting effect of $I_{\mathrm{h}}$ is achieved through the activation of non-inactivating, voltage-gated potassium conductances (George et al., 2008). These results showed that RMP depolarization by $I_{h}$ leads to a steady-state activation of $\mathrm{K}^{+}$channel, which may produce dual excitatory and inhibitory effects of $I_{\mathrm{h}}$ depending on the input strength. Computational and experimental data suggested that a physiological candidate for the $\mathrm{K}^{+}$current was the M-current, whose regulation through neuromodulation may switch the role of $I_{\mathrm{b}}$ in signal integration from inhibitory to excitatory (George et al., 2008). In the febrile seizure model, we reported a downregulation of a presumed persistent potassium current (Dyhrfjeld-Johnsen et al., 2008), suggesting a reduction of such an interaction as an additional mechanism for increased excitability following the h-current upregulation.

Increased $I_{\mathrm{h}}$ may also interact with inhibitory synaptic inputs resulting in post-inhibitory rebound firing in CA1 pyramidal cells after febrile seizures (Chen et al., 2001a), and a similar effect is well-known to occur in thalamo-cortical projection neurons (Crunelli and Leresche, 1991; Soltesz et al., 1991). Additionally, depolarized dendritic membrane potentials could facilitate the propagation of distal dendritic $\mathrm{Ca}^{2+}$-spikes to the soma (Jarsky et al., 2005). Conversely, the membrane hyperpolarization following the reduction of $I_{\mathrm{h}}$ has been shown to release constraints on distal dendritic $\mathrm{Ca}^{2+}$ spikes (Tsay et al., 2007), suggesting a potential pro-excitatory role for downregulation of the h-current in epilepsy.

Finally, in the post-traumatic, hyperexcitable dentate gyrus, mossy cells exhibit extensive modifications in $\mathrm{Na}^{+}, \mathrm{K}^{+}$, and h-currents, without altered I-F and I-V curves (Howard et al., 2007). The importance of the opposing, apparently coordinated and homeostatic-like changes in several conductances of single neurons was elucidated computationally in a realistic large-scale model of the dentate gyrus (Dyhrfjeld-Johnsen et al., 2007; Howard et al., 2007), demonstrating that individually the ion channel perturbations could significantly affect network activity.

\section{SUMMARY AND CONCLUSION}

In CA1 pyramidal cell models, only an increased functional $I_{\mathrm{h}}$ appears to be underlying direct proexcitatory effects on single neuron firing, as previously demonstrated in three different CA1 neuron computational models of widely differing complexity (Dyhrfjeld-Johnsen et al., 2008). However, as the result depends on the balance between the effects on RMP and $R_{\text {in }}$, the conclusion could be affected by other intrinsic properties determined by neuron type, developmental stage, and neuromodulation. Furthermore, through interaction with other voltage-gated and ligand-gated conductances (Dyhrfjeld-Johnsen et al., 2008; George et al., 2008; Howard et al., 2007; Tsay et al., 2007), normal and altered h-current may modify neuronal excitability in a complex fashion.

Additionally, the h-current is involved in determining resonance frequencies of neurons (Hu et al., 2002; Wang et al., 2006) and likely to play a significant role in pathological network oscillatory behavior in epilepsy. In recent years, the response of CA1 pyramidal neurons to the hippocampal theta rhythm has been shown to be impaired due to the downregulated h-current in the pilocarpine model of temporal lobe epilepsy (Marcelin et al., 2009). This finding suggests additional roles for h-channelopathies in impaired learning and memory (Nolan et al., 2003, 2004). Finally, neurons with high $I_{\mathrm{h}}$ have recently been implicated in the initiation of highly excitable, network-wide UP states (Kang et al., 2008).

While this focused review concentrates on channelopathic alteration of the h-current in pyramidal neuron dendrites, $I_{\mathrm{h}}$ is also expressed in axonal terminals (Bender et al., 2007; Lujan et al., 2005) and inhibitory interneurons (Aponte et al., 2006; Lupica et al., 2001; Maccaferri and McBain, 1996). Along with the complex effects on pyramidal neuron excitability discussed above, it is emphasized that factors ranging from direct effects on RMP and $R_{\text {in }}$ to interactions with other ion channels, h-channel localization, and neuronal subtype must be taken into account when judging whether upregulation or downregulation of $I_{\mathrm{h}}$ leads to hyperexcitability in a given animal model.

\section{ACKNOWLEDGEMENT}

The work is supported by the Epilepsy Foundation/ Milken Family Foundation (EFA-36656 to JDJ) and the NIH (NS38580 to IS). 


\section{REFERENCES}

Aponte, Y., Lien, C. C., Reisinger, E., and Jonas, P. (2006). Hyperpolarizationactivated cation channels in fast-spiking interneurons of rat hippocampus. J. Physiol. 574, 229-243.

Avanzini, G., Franceschetti, S., and Mantegazza, M. (2007). Epileptogenic channelopathies: experimental models of human pathologies. Epilepsia 48(Suppl. 2), 51-64.

Beck, H., and Yaari, Y. (2008). Plasticity of intrinsic neuronal properties in CNS disorders. Nat. Rev. Neurosci. 9, 357-369.

Becker, A. J., Pitsch, J., Sochivko, D., Opitz, T., Staniek, M., Chen, C. C., Campbell, K. P., Schoch, S., Yaari, Y., and Beck, H. (2008). Transcriptional upregulation of Cav3.2 mediates epileptogenesis in the pilocarpine model of epilepsy. J. Neurosci. 28, 13341-13353.

Bender, R. A., Kirschstein, T., Kretz, O., Brewster, A. L., Richichi, C., Ruschenschmidt, C., Shigemoto, R., Beck, H., Frotscher, M., and Baram, T. Z. (2007). Localization of HCN1 channels to presynaptic compartments: novel plasticity that may contribute to hippocampal maturation. J. Neurosci. 27, 4697-4706.

Bernard, C., Anderson, A., Becker, A., Poolos, N.P., Beck, H., and Johnston, D. (2004). Acquired dendritic channelopathy in temporal lobe epilepsy. Science 305, 532-535.

Brager, D. H., and Johnston, D. (2007). Plasticity of intrinsic excitability during long-term depression is mediated through mGluR-dependent changes in $\mathrm{I}(\mathrm{h})$ in hippocampal CAl pyramidal neurons. J. Neurosci. 27, 13926-13937.

Brewster, A., Bender, R. A., Chen, Y., Dube, C., Eghbal-Ahmadi, M., and Baram, T. Z. (2002). Developmental febrile seizures modulate hippocampal gene expression of hyperpolarizationactivated channels in an isoform- and cell-specific manner. J. Neurosci. 22, 4591-4599.

Brewster, A. L., Bernard, J. A., Gall, C. M., and Baram, T. Z. (2005). Formation of heteromeric hyperpolarizationactivated cyclic nucleotide-gated $(\mathrm{HCN})$ channels in the hippocampus is regulated by developmental seizures. Neurobiol. Dis. 19, 200-207.

Brooks-Kayal, A. R., Shumate, M. D. Jin, H., Rikhter, T.Y., and Coulter, D. A. (1998). Selective changes in single cell $\mathrm{GABA}(\mathrm{A})$ receptor subunit expression and function in temporal lobe epilepsy. Nat. Med. 4, 1166-1172.

Catterall, W. A., Dib-Hajj, S., Meisler, M. H., and Pietrobon, D. (2008). Inherited neuronal ion channelopathies: new windows on complex neurological diseases. J. Neurosci. 28 , 11768-11777.

Chen, K., Aradi, I., Thon, N., EghbalAhmadi, M., Baram, T. Z., and Soltesz, I. (2001a). Persistently modified h-channels after complex febrile seizures convert the seizure-induced enhancement of inhibition to hyperexcitability. Nat. Med. 7, 331-337.

Chen, S., Wang, J., and Siegelbaum, S. A. (2001b). Properties of hyperpolarization-activated pacemaker current defined by coassembly of HCN1 and HCN2 subunits and basal modulation by cyclic nucleotide. J. Gen. Physiol. 117, 491-504.

Crunelli, V., and Leresche, N. (1991). A role for $\mathrm{GABAB}$ receptors in excitation and inhibition of thalamocortical cells. Trends Neurosci. 14, 16-21.

DiFrancesco, D. (1993). Pacemaker mechanisms in cardiac tissue. Annu. Rev. Physiol. 55, 455-472.

Dyhrfjeld-Johnsen, J., Morgan, R. J., Foldy, C., and Soltesz, I. (2008). Upregulatedh-currentinhyperexcitable cal dendrites after febrile seizures. Front. Cell. Neurosci. 2, 2.

Dyhrfjeld-Johnsen, J., Santhakumar, V., Morgan, R. J., Huerta, R., Tsimring, L., and Soltesz, I. (2007). Topological determinants of epileptogenesis in large-scale structural and functional models of the dentate gyrus derived from experimental data. $J$. Neurophysiol. 97, 1566-1587.

Ellerkmann, R. K., Remy, S., Chen, J. Sochivko, D., Elger, C. E., Urban, B. W., Becker, A., and Beck, H. (2003). Molecular and functional changes in voltage-dependent $\mathrm{Na}(+)$ channels following pilocarpine-induced status epilepticus in rat dentate granule cells. Neuroscience 119, 323-333.

Fan, Y., Fricker, D., Brager, D. H., Chen, X., Lu, H. C., Chitwood, R. A., and Johnston, D. (2005). Activitydependent decrease of excitability in rat hippocampal neurons through increases in I(h). Nat. Neurosci. 8, 1542-1551.

Fogle, K. J., Lyashchenko, A. K., Turbendian, H. K., and Tibbs, G. R. (2007). HCN pacemaker channel activation is controlled by acidic lipids downstream of diacylglycerol kinase and phospholipase A2. J. Neurosci. 27, 2802-2814.

George, M. S., Abbott, L. F., and Siegelbaum, S. A. (2008). Excitatory and inhibitory roles for the hyperpolarization-activated current in CA1 pyramidal neurons. Poster 33. 2/D60 presented at The Annual Meeting of the Society for Neuroscience 2008.

Golding, N. L., Kath, W. L., and Spruston, N. (2001). Dichotomy of action-potential backpropagation in
CA1 pyramidal neuron dendrites. J. Neurophysiol. 86, 2998-3010.

Hirose, S., Mitsudome, A., Okada, M., and Kaneko, S. (2005). Genetics of idiopathic epilepsies. Epilepsia 46(Suppl. 1), 38-43.

Howard, A. L., Neu, A., Morgan, R. J., Echegoyen, J. C., and Soltesz, I. (2007). Opposing modifications in intrinsic currents and synaptic inputs in posttraumatic mossy cells: evidence for single-cell homeostasis in a hyperexcitable network. J. Neurophysiol. 97, 2394-2409.

Hu, H., Vervaeke, K., and Storm, J. F (2002). Two forms of electrical resonance at theta frequencies, generated by M-current, h-current and persistent $\mathrm{Na}+$ current in rat hippocampal pyramidal cells. J. Physiol. 545, 783-805.

Jarsky, T., Roxin, A., Kath, W. L., and Spruston, N. (2005). Conditional dendritic spike propagation following distal synaptic activation of hippocampal CA1 pyramidal neurons. Nat. Neurosci. 8, 1667-1676.

Jung, S., Jones, T. D., Lugo, J. N., Jr. Sheerin,A. H., Miller, J. W., D’Ambrosio, R., Anderson, A. E. and Poolos, N. P. (2007). Progressive dendritic HCN channelopathy during epileptogenesis in the rat pilocarpine model of epilepsy. J. Neurosci. 27, 13012-13021.

Kang, S., Kitano, K., and Fukai, T. (2008). Structure of spontaneous UP and DOWN transitions self-organizing in a cortical network model. PLoS Comput. Biol. 4, e1000022.

Kaupp, U. B., and Seifert, R. (2002). Cyclic nucleotide-gated ion channels. Physiol. Rev. 82, 769-824.

Lerche, H., Weber, Y. G., Jurkat-Rott, K. Lehmann-Horn, F. (2005). Ion channel defects in idiopathic epilepsies. Curr. Pharm. Des. 11, 2737-2752.

Lorincz, A., Notomi, T., Tamas, G., Shigemoto, R., and Nusser, Z. (2002). Polarized and compartmentdependent distribution of $\mathrm{HCN} 1$ in pyramidal cell dendrites. Nat. Neurosci. 5, 1185-1193.

Lujan, R.,Albasanz,J.L., Shigemoto, R., and Juiz, J. M. (2005). Preferential localization of the hyperpolarization-activated cyclic nucleotide-gated cation channel subunit $\mathrm{HCN} 1$ in basket cell terminals of the rat cerebellum. Eur. J. Neurosci. 21, 2073-2082.

Lupica, C. R., Bell, J. A., Hoffman, A. F., and Watson, P.L. (2001). Contribution of the hyperpolarization-activated current $(\mathrm{I}(\mathrm{h})$ ) to membrane potential and GABA release in hippocampal interneurons. J. Neurophysiol. 86 , 261-268.

Maccaferri, G., and McBain, C. J. (1996). The hyperpolarization-activated cur- rent (Ih) and its contribution to pacemaker activity in rat CA1 hippocampal stratum oriens-alveus interneurones. J. Physiol. 497(Pt 1), 119-130.

Magee, J. C. (1998). Dendritic hyperpolarization-activated currents modify the integrative properties of hippocampal CAl pyramidal neurons. J. Neurosci. 18, 7613-7624.

Marcelin B., Chauvière, L., Becker, A., Migliore, M., Esclapez, M., and Bernard, C. (2009). h channeldependent deficit of theta oscillation resonance and phase shit in temporal lobe epilepsy. Neurobiol. Dis. 33, 436-447.

McClelland, S., Richichi, C., Dube, C. Zha, Q., and Baram, T. Z. (2008). Activity-dependent increase of NRSF/ REST levels suppresses expression of the hyperpolarization activated cyclic-nucleotide gated (HCN) channel. Poster 33. 7/D65 presented at The Annual Meeting of the Society for Neuroscience 2008.

Mulley, J. C., Scheffer, I. E., Petrou, S., and Berkovic, S.F. (2003). Channelopathies as a genetic cause of epilepsy. Curr. Opin. Neurol. 16, 171-176.

Munsch, T., and Pape, H. C. (1999). Modulation of the hyperpolarizationactivated cation current of rat thalamic relay neurones by intracellular $\mathrm{pH}$. $J$. Physiol. 519(Pt 2), 493-504.

Noam, Y., Zha, Q., Wu, R. L., Phan, L. Chetkovich, D. M., Wadman, W. J., and Baram, T. Z. (2008). Dynamic trafficking of HCN1 channels in hippocampal neurons: live-imaging studies. Poster 33. 1/D59 presented at The Annual Meeting of the Society for Neuroscience 2008.

Nolan, M. F., Dudman, J.T., Dodson, P. D., and Santoro, B. (2007). HCN1 channels control resting and active integrative properties of stellate cells from layer II of the entorhinal cortex. J. Neurosci. 27, 12440-12451.

Nolan, M. F., Malleret, G., Dudman, J. T., Buhl, D. L., Santoro, B., Gibbs, E., Vronskaya, S., Buzsaki, G., Siegelbaum, S. A., Kandel, E. R., and Morozov, A. (2004). A behavioral role for dendritic integration: HCN1 channels constrain spatial memory and plasticity at inputs to distal dendrites of CA1 pyramidal neurons. Cell 119, 719-732.

Nolan, M. F., Malleret, G., Lee, K. H., Gibbs, E., Dudman, J. T., Santoro, B., Yin, D., Thompson, R. F., Siegelbaum,S. A., Kandel, E. R., and Morozov, A. (2003). The hyperpolarization-activated $\mathrm{HCN} 1$ channel is important for motor learning and neuronal integration by cerebellar Purkinje cells. Cell 115, 551-564.

Pitkanen, A., and Lukasiuk, K. (2009). Molecular and cellular basis of epi 
leptogenesis in symptomatic epilepsy. Epilepsy Behav. 14(Suppl. 1), 16-25.

Poirazi, P., Brannon, T., and Mel, B. W. (2003). Arithmetic of subthreshold synaptic summation in a model CA1 pyramidal cell. Neuron 37, 977-987.

Poolos, N. P. (2004). The Yin and Yang of the h-channel and its role in epilepsy. Epilepsy Curr. 4, 3-6.

Poolos, N. P., Bullis, J. B., and Roth, M. K. (2006). Modulation of h-channels in hippocampal pyramidal neurons by p38 mitogen-activated protein kinase. J. Neurosci. 26, 7995-8003.

Poolos, N.P., Migliore, M., and Johnston, D. (2002). Pharmacological upregulation of h-channels reduces the excitability of pyramidal neuron dendrites. Nat. Neurosci. 5, 767-774.

Robinson, R. B., and Siegelbaum, S. A. (2003). Hyperpolarization-activated cation currents: from molecules to physiological function. Annu. Rev. Physiol. 65, 453-480.

Sanchez, R. M., Dai, W., Levada, R. E., Lippman, J. J., and Jensen, F. E. (2005). AMPA/kainate receptor-mediated downregulation of GABAergic synaptic transmission by calcineurin after seizures in the developing rat brain. J. Neurosci. 25, 3442-3451.

Santoro, B., Wainger, B. J., and Siegelbaum, S. A. (2004). Regulation of HCN channel surface expres- sion by a novel C-terminal proteinprotein interaction. J. Neurosci. 24 , 10750-10762.

Shah, M. M., Anderson, A. E., Leung, V., Lin, X., and Johnston, D. (2004). Seizure-induced plasticity of h channels in entorhinal cortical layer III pyramidal neurons. Neuron 44, 495-508.

Shin, M., Brager, D., Jaramillo, T. C., Johnston, D., and Chetkovich, D. M. (2008). Mislocalization of $h$ channel subunits underlies $\mathrm{h}$ channelopathy in temporal lobe epilepsy. Neurobiol. Dis. 32, 26-36.

Shin, M., and Chetkovich, D. M. (2007). Activity-dependent regulation of $h$ channel distribution in hippocampal CAl pyramidal neurons.J. Biol. Chem. 282, 33168-33180.

Shruti, S., Clem, R. L., and Barth, A. L. (2008). A seizure-induced gain-of-function in BK channels is associated with elevated firing activity in neocortical pyramidal neurons. Neurobiol. Dis. 30, 323-330.

Soltesz, I., Lightowler, S., Leresche, N., Jassik-Gerschenfeld, D., Pollard, C. E., and Crunelli, V. (1991). Two inward currents and the transformation of low-frequency oscillations of rat and cat thalamocortical cells. J. Physiol. 441, 175-197.

Su, H., Sochivko, D., Becker, A., Chen, J., Jiang, Y., Yaari, Y., and Beck, H. (2002).
Upregulation of a T-type Ca2+ channel causes a long-lasting modification of neuronal firing mode after status epilepticus. J. Neurosci. 22, 3645-3655.

Tsay,D.,Dudman,J.T., andSiegelbaum, S. A (2007). HCN1 channels constrain synaptically evoked $\mathrm{Ca} 2+$ spikes in distal dendrites of CA1 pyramidal neurons. Neuron 56, 1076-1089.

van Welie, I., van Hooft, J. A., and Wadman, W. J. (2004). Homeostatic scaling of neuronal excitability by synaptic modulation of somatic hyperpolarization-activated Ih channels. Proc. Natl. Acad. Sci. U.S.A. 101, 5123-5128.

Wainger, B. J., DeGennaro, M., Santoro, B., Siegelbaum, S. A., and Tibbs, G. R. (2001). Molecular mechanism of cAMP modulation of HCN pacemaker channels. Nature 411, 805-810.

Wang, W.T., Wan, Y.H.,Zhu, J.L., Lei, G. S. Wang, Y. Y., Zhang, P., and Hu, S. J. (2006). Theta-frequency membrane resonance and its ionic mechanisms in rat subicular pyramidal neurons. Neuroscience 140, 45-55.

Zha, Q., Brewster, A. L., Richichi, C., Bender, R. A., and Baram, T.Z. (2008) Activity-dependent heteromerization of the hyperpolarization-activated, cyclic-nucleotide gated (HCN) channels: role of $\mathrm{N}$-linked glycosylation. J. Neurochem. 105, 68-77.
Zhang, K., Peng, B. W., and Sanchez, R. M. (2006). Decreased IH in hippocampal area CA1 pyramidal neurons after perinatal seizure-inducing hypoxia Epilepsia 47, 1023-1028.

Zolles, G., Klocker, N., Wenzel, D., WeisserThomas, J., Fleischmann, B. K., Roeper, J., and Fakler, B. (2006). Pacemaking by $\mathrm{HCN}$ channels requires interaction with phosphoinositides. Neuron 52, 1027-1036.

Conflict of Interest Statement: The authors declare that the research was conducted in the absence of any commercial or financial relationships that could be construed as a potential conflict of interest.

Received: 01 February 2009; paperpending published: 19 February 2009; accepted: 04 March 2009; published: 01 May 2009.

Citation: Front. Neurosci. (2009) 3,1: 25-33. doi: 10.3389/neuro.01.005.2009

Copyright (c) 2009 Dyhrfjeld-Johnsen, Morgan and Soltesz. This is an openaccess article subject to an exclusive license agreement between the authors and the Frontiers Research Foundation, which permits unrestricted use, distribution, and reproduction in any medium, provided the original authors and source are credited. 